\title{
Treatment Interruption Among Drug-Susceptible Pulmonary Tuberculosis Patients in Southern Ethiopia
}

\author{
Moges Getie Workie' \\ Moges Wubie Aycheh ${ }^{2}$ \\ Molla Yigzaw Birhanu (D) ${ }^{2}$ \\ Tesfa Birlew Tsegaye (D) ${ }^{2}$ \\ 'Public Health, Ari Primary Hospital, \\ Gazer, Southern Nations, Nationalities, \\ and Peoples' Region, Ethiopia; \\ ${ }^{2}$ Department of Public Health, College of \\ Health Sciences, Debre Markos \\ University, Debre Markos, Ethiopia
}

Background: Tuberculosis treatment interruption is a failure of attending two scheduled appointments to collect the drugs in either phase of tuberculosis treatment. Even if TB treatment is crucial to achieve a cure and avoid the emergence of drug resistance, treatment interruption is the most testing and deterring factor for successful tuberculosis treatment and one of the problems leading to the development of drug-resistant tuberculosis. TB treatment interruption is the precursor for loss to follow-up and treatment failure, but the magnitude of this problem is unknown in Ethiopia. Thus, this study was intended to identify determinants of treatment interruption among drug-susceptible pulmonary tuberculosis patients in South Ari district, Southern Ethiopia.

Methods: An institution-based unmatched case control study was conducted from February through April 2020 using 255 samples with a ratio of 2:1 (controls to cases). Data were entered into Epi data version 4.2 and exported for analysis using STATA 14.0 statistical software. The variables having a p-value of less than 0.25 in the bivariable analysis were subjected to multivariable logistic regression analysis. In multivariable logistic regression analysis, AORs, $95 \%$ CIs, and p-values of $<0.05$ were used to identify significant variables. Results: The median age was 34 (IQR: 18) years in cases and 29 (IQR: 16) years in control groups. Significant factors that were associated with treatment interruption were alcohol consumption $(\mathrm{AOR}=2.99,95 \% \mathrm{CI}$; 1.41-6.36); smoking habits $(\mathrm{AOR}=2.82,95 \% \mathrm{CI}$; 1.14-6.94); use of traditional medicine (AOR $=2.35,95 \%$ CI 1.05-5.24); co-infected with $\mathrm{HIV}(\mathrm{AOR}=1.58,95 \% \mathrm{CI} ; 1.85-4.29$ ), and waiting time at the health facility $\geq 30$ minutes (AOR $=2.98,95 \% \mathrm{CI} ; 1.31-6.80)$.

Conclusion: Alcohol consumption, waiting time at the health facility $\geq 30$ minutes, smoking habits, used traditional medicine, and HIV co-infected were potential determinants. Enhancing public health education, designing strategies that emphasize patients with HIV coinfection, and reducing waiting times are recommended.

Keywords: treatment interruption, susceptible, pulmonary tuberculosis, directly observed treatment, drug resistant tuberculosis

\section{Background}

Tuberculosis (TB) is an infectious disease caused by a group of Mycobacterium species called Mycobacterium tuberculosis complex. It is a major public health problem throughout the world that infects about one-third of the world's population and puts them at risk of developing active disease during their lifetime. ${ }^{1}$ It is characterized by the formation of tubercles in the lungs and other tissues of the body, often developing long after the initial infection. Mostly, it affects the lung
Correspondence: Molla Yigzaw Birhanu; Tesfa Brilew Tsegaye

Tel +25I 9106I4947; +25I 913310476

Email mollayigzaw33@gmail.com;

tesfabirlew@yahoo.com 
parenchyma tissue, which is called pulmonary tuberculosis. However, it can spread to other organs, causing extra pulmonary tuberculosis (ETB). ${ }^{2,3}$ Mycobacterium tuberculosis (MTB) is the commonest but human infection with $M$. bovis has decreased significantly in developed countries as a result of pasteurization. ${ }^{4}$ Three factors determine the likelihood of Mycobacterium tuberculosis transmission: the number of organisms expelled into the air, the concentration of organisms in the air, and length of time an exposed person breathes contaminated air. ${ }^{5,6}$

Tuberculosis treatment interruption is a failure of attending two scheduled appointments to collect drugs either in the intensive phase or the continuation phase of tuberculosis treatment. ${ }^{7}$ It is one of the problems leading to the development of drug resistant tuberculosis. ${ }^{8,9}$ It is also a precursor for lost to follow-up and treatment failure. ${ }^{3,10}$ Failure to cure increases the risk of development of drug resistant strains and further spread of TB in the community. ${ }^{11}$ The magnitude of treatment interruption is $19 \%, 31 \%, 40 \%$ and $36 \%$ in Nigeria, Kenya, Lagos (Nigeria) and Russia, respectively, but is not known in Ethiopia. ${ }^{3,12-14}$ Treatment interruption contributes greatly to Ethiopia being one of the 20 countries with the highest estimated numbers of incident multidrugresistant tuberculosis (MDR TB) cases that together contribute $87 \%$ of the global burden. ${ }^{15}$ The emergence of drug resistant tuberculosis (DR-TB) is a challenge for global control and prevention of the disease. ${ }^{16}$

Adherence is a very complex issue, determined by patient factors, service-related factors, as well as patients' and caregivers' attitudes, knowledge and perceptions of tuberculosis. ${ }^{17}$ It is crucial to achieve a cure and avoid emergence of drug resistance. ${ }^{11}$

Even though studies have been conducted on risk factors for drug resistant tuberculosis (DR-TB) there is no evidence on the factors contributing to tuberculosis treatment interruption in Ethiopia that would make it possible to address the effect of treatment interruption on treatment success, lost to follow up, treatment failure and drug resistance. ${ }^{18,19}$ Hence, this study tried to identify determinants of treatment interruption among drug susceptible pulmonary tuberculosis patients in Southern Ethiopia.

\section{Methods}

\section{Study Design, Area and Period}

An institution-based unmatched case-control study was conducted in the south region, South Omo Zone, South Ari district from February to April, 2020. The district is located $699 \mathrm{~km}$ southwest of Addis Ababa and $571 \mathrm{~km}$ from Hawassa, which is the capital city of southern nation nationalities and the seat of the people's regional government. The district has one primary hospital, 9 health centers, and 52 health posts. It also has 5 private clinics but they are not tuberculosis treatment centers. The district boasts resources like arable land, livestock, pasture land and medicinal plants. Agriculture is the main economic activity, with most households earning a living from arable farming, cash crops (sugarcane, mace (cardamom) and coffee), and livestock-keeping for dairy products.

\section{Study Population}

The study population comprised all pulmonary tuberculosis patients who were on TB treatment in South Ari district, Southern Ethiopia registered between September 27, 2019 to January 28, 2020.

Cases comprised pulmonary tuberculosis patients who had received treatment for at least 4 weeks and had interrupted their treatment either in the intensive or continuation phases, regardless of whether they returned to therapy or not, registered between September 27, 2019 to January 28, 2020 and aged $\geq 15$ years.

Controls comprised pulmonary tuberculosis patients who had received treatment for at least 4 weeks and were non-interrupters in either in the intensive or continuation phases, registered between September 27, 2019 to January 28, 2020 and aged $\geq 15$ years.

\section{Eligibility Criteria}

Inclusion criteria were that pulmonary tuberculosis patients had received treatment for at least 4 weeks and had been registered between the dates stated above and were aged $\geq 15$ years.

The exclusion criterion was that patients had transferred out of the study area.

\section{Sample Size Determination and Sampling Techniques}

The sample size was calculated using a double proportion formula based on the following assumption and information: $95 \%$ confidence interval at $80 \%$ of power, with 2:1 controls to cases ratio, and a proportion of drug side effects among interrupters of $76.9 \%$, and among non-interrupters of $57.5 \%$. Using the above assumption and information, the minimum sample size calculated using the double population proportion formula was 
231 (77 cases and 154 controls). With a 10\% nonresponse rate for both cases and controls, the total sample size was $255(10 \times 231=23+231=255)$. The sample size for the second objective (associated factors) was calculated for the following significant variables: alcohol consumption, personal monthly income $\leq \$ 100$ (10,000 Kenyan shillings) and waiting time at the health facility; we considered the sample size calculated for the first objective since it gave a larger sample size. ${ }^{3}$

The district was stratified in to a hospital and health centers based on availability of facilities/services/quality of service provision. The health centers were also stratified based on availability of facilities/services/quality of service provision, and whether or not the TB clinic personnel were trained. Proportional allocation was used to select samples from each stratum. Before data collection, a census was conducted to identify the total number of eligible TB patients to be included in the study and also to identify all cases and controls from each health facility by reviewing the TB units' registration books and allocating the number of samples proportionally for each health center and hospital. Cases and controls were identified using a computer-generated random sampling method based on data from the TB registration books of hospitals and clinics.

\section{Study Variables}

The dependent variable of this study was treatment interruption. There were four sets of explanatory variables: (1) socio-demographic characteristics, such as age, occupation, physical activity, residence and educational status; (2) patients' knowledge of TB treatment; (3) patients' behavioral characteristics, such as smoking and drinking; and (4) care provider-related characteristics.

\section{Operational Definitions}

Treatment interruption is a failure to attend two scheduled appointments to collect drugs either in the intensive phase or the continuation phase of treatment. Tuberculosis (TB) is an infectious disease of the lungs caused by Mycobacteriumtuberculosis. Behavioral factors refer to the effects of patients' personalities and responses to their environment on their daily activities.

\section{Data Collection and Quality Control Methods}

The questionnaire/tool was prepared in English, converted to Amharic and then converted back to English to check the consistency of the data. In this study, both primary and secondary sources of data were used. An interviewer administered structured questionnaire was used to gain primary data and secondary data were extracted from TB registration books. The data were collected and extracted by five data collectors (3 Diploma nurses and $2 \mathrm{BSc}$ nurses) and 3 supervisors ( 2 health officers and $1 \mathrm{MPH}$ ). Data quality was assured by providing training for data collectors and supervisors, close daily supervision by principal investigators, proper handling of the data, and using Epidata for data entry. A pre-test was also conducted to check that the understanding of study participants was consistently in line with the needs of the principal investigators.

\section{Data Management and Analysis}

Data were checked for completeness, edited, coded and entered into Epidata version 4.2 and exported into STATA version 14.0 statistical software for further management and analysis. Descriptive statistics were computed using frequencies with proportions to summarize categorical data and means with standard deviations to summarize normally distributed continuous data as well as median with the interquartile range for non-normally distributed continuous data. To identify variables associated with drug-interruption among TB patients, a binary logistic regression model was used. Variables in the bivariable analysis having p-values of less than 0.25 were eligible for multivariable logistic regression analysis. The model fitness was checked by Hosmer and Lemeshow's statistic with a cutoff point of $p$-value $\geq 0.05$. Multi-colinearity, checked by the variance inflation factor, was 1.03-1.16 (mean vif; 1.09). Finally, variables having p-values of less than 0.05 in the multivariable logistic regression analysis model with a 95\% confidence interval (CI) and corresponding adjusted odds ratio were used to declare the presence and/or absence and strength of statistical associations.

\section{Results}

\section{Socio-Demographic Characteristics}

Among cases and controls who participated in the study, $57(69.51 \%)$ and $98(58.68 \%)$ of the TB patients were males, respectively. The median age was 34 (IQR: 18) years for cases and 29 (IQR: 16) years for controls. Those aged between 25 and 34 years accounted for the majority of patients in both cases $(33,40.24 \%)$ and 
controls $(58,34.73 \%)$. The majority of patients were illliterate: 51 cases $(62.20 \%)$ and 62 controls $(37.13 \%)$. More than half of cases $(49,59.76 \%)$ and controls $(95$, $56.89 \%$ ) were Ari by ethnicity. Forty-one $(50.0 \%)$ cases were protestant by religion but Orthodox Christians accounted for the majority of controls (57, $34.13 \%)$. The majority of participants were rural dwellers, accounting for 63 cases $(76.83 \%)$ and 89 controls (53.29\%). The majority of cases had one to three children $(38,46.34 \%)$; however, a family size of four to six children was usual in controls $(76,45.54 \%)$

\section{Knowledge of TB Treatment}

The mean knowledge score for the respondents was 2.5 and 3.44 for cases and controls, respectively. Ten (5.99\%) of the respondents were able to answer all questions correctly in the control group but no one was able to answer all questions in the case group. Thirty-three cases (40.24\%) and 25 controls (14.97\%) gained the minimum knowledge score. More than half $(48,58.54 \%)$ of cases recognized "the disease called drug resistant tuberculosis" but, of controls, $112(67.07 \%)$ knew "the duration of tuberculosis treatment". From 82 cases, 56 (68.29\%) gained a poor knowledge score and, from 167 controls, 77 (46.11\%) gained a poor knowledge score.

\section{Behavioral Related Factors in Treatment Interruption}

Fifty-one cases $(62.20 \%)$ and 40 controls $(24.00 \%)$ had a history of alcohol consumption. Twenty-five cases $(49.10 \%)$ consumed alcohol daily and 16 controls $(40.00 \%)$ consumed alcohol occasionally. Thirty-two (39.02\%) cases and $46(27.54 \%)$ controls were current khat users. From all current khat users, those who use at least once a week represented more than half of cases $(25$, $78.12 \%$ ); however, in controls, those who use less than once a week were the majority $(27,58.70 \%)$. Among all study participants, 36 cases $(43.90 \%)$ and 28 controls (16.77\%) were smokers. Daily smokers and occasional smokers were the majority in cases and controls, respectively.

\section{Patient Related Factors in Treatment Interruption}

Most of the respondents were smear positive pulmonary tuberculosis patients: 75 cases (91.46\%) and 142 controls (85.03\%) More than half of the participants were new tuberculosis cases: 50 cases $(60.98 \%)$ and 134 controls 134 (80.24\%). Twenty- seven cases (32.93\%) and 50 controls (29.94\%) reported experiencing drug side effects. Thirty-one cases $(37.80 \%)$ and 27 controls (16.17\%) were co-infected with HIV. Thirtyfour cases (41.46\%) and 22 controls (13.17\%) reported use of traditional/herbal medicine during their TB treatment. More controls (41.92\%) than cases (34.15\%) reported feeling better early ( $<2$ weeks) during TB treatment.

Among the total cases who participated in the study, 36 $(43.90 \%)$ missed their scheduled appointment in both the intensive and continuation phases, 26 (31.71\%) missed their scheduled appointment in the continuation phase, and $20(24.39 \%)$ missed their scheduled appointment in the intensive phase (Figure 1).

\section{Care Provider and System Related Factors}

Among cases who participated in the study, 53 (64.63\%) traveled 1 hour or more to reach the treatment site, 46 $(56.10 \%)$ traveled on foot, $34(41.46 \%)$ reported $30 \mathrm{~min}-$ utes or more waiting time at treatment site, 26 (31.71\%) were not counseled before initiation of treatment, 61 $(74.39 \%)$ did not have TB treatment supporter, 17 (20.73\%) reported a shortage of drugs, 29 (35.37\%) experienced stigmatization, and $58(70.73 \%)$ did not have a mobile phone. Among controls, 106 (63.47\%) traveled less than 1 hour to reach the treatment site, 93 $(55.69 \%)$ traveled on foot, $139(83.23 \%)$ reported less than 30 minutes waiting time, 38 (22.75\%) were not counseled before initiation of tuberculosis treatment, $55(32.93 \%)$ did not have TB treatment supporter, 27 (16.17\%) reported a shortage of drugs, 28 (16.77\%) experienced stigmatization, and 77 (46.11\%) did not have a mobile phone.

\section{Determinant of Treatment Interruption}

In the bivariable analysis, ages $15-24$ years and $\geq 55$ years, marital status, level of knowledge, alcohol consumption, smoking habits, TB category, HIV co-infection, sputum result at diagnosis, use of traditional/herbal medicine, TB treatment supporter, waiting time at health facility and stigmatization were significantly associated with TB treatment interruption. However, in the multivariable analysis, alcohol consumption, smoking habits, HIV co-infection, traditional/herbal medicine use and waiting time at health facility were significantly associated with TB treatment interruption.

The odds of tuberculosis treatment interruption among TB patients who consumed a lot of alcohol were 2.99 


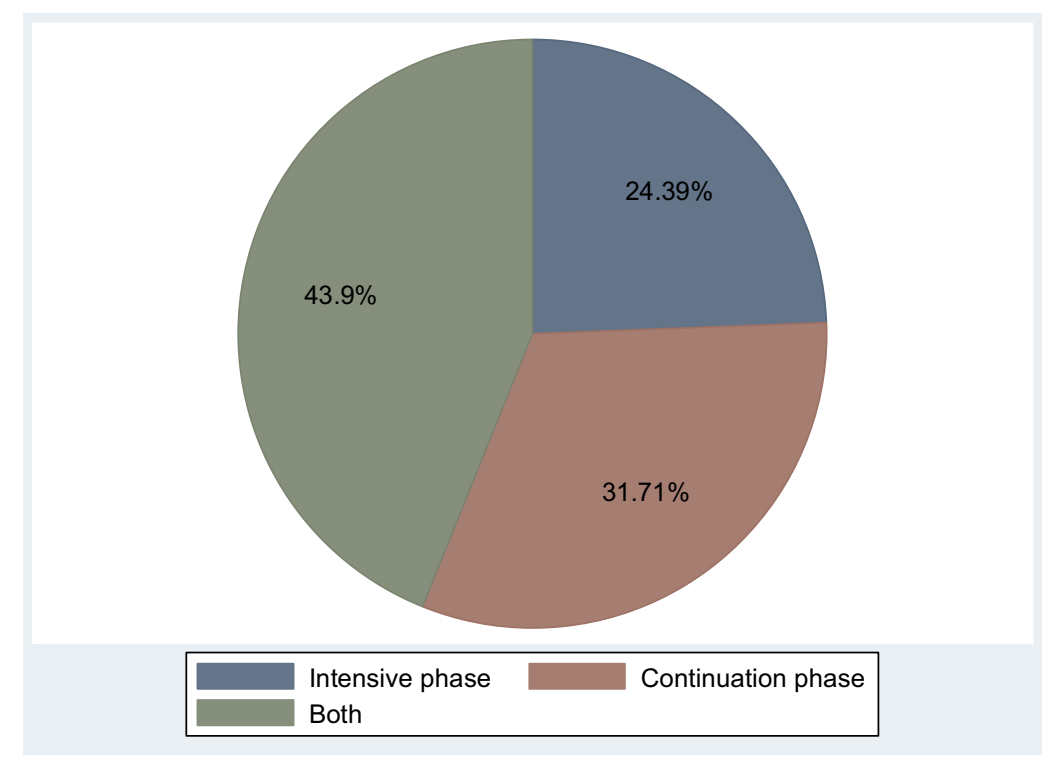

Figure I Proportion of cases and phases of treatment interruption in South Ari District, Southern Ethiopia, 2020.

times greater compared to their counterparts (adjusted odds ratio $[\mathrm{AOR}]=2.99 ; 95 \% \mathrm{CI}: 1.41-6.36$, p-value $=$ 0.004). The odds of TB treatment interruptions among smokers was 2.82 (AOR $=2.82 ; 95 \%$ CI: 1.14-6.94, p-value $=0.02$ ) times greater than non-smokers. The odds of tuberculosis treatment interruption among those who used traditional/herbal medicine were 2.35 times higher than that of their counterparts (AOR $=2.35 ; 95 \%$ CI: 1.05-5.24, p-value $=0.04)$. TB/HIV co-infected patients were 1.58 times more likely to interrupt their TB treatment compared to uninfected TB patients (AOR = $1.58 ; 95 \%$ CI: $1.85-4.29, \mathrm{p}$-value $=0.03)$. Those TB patients who waited $\geq 30$ minutes at the health facility were 2.98 times more likely to interrupt their TB treatment compared to $\mathrm{TB}$ patients who waited $<30$ minutes (AOR $=$ 2.98; 95\% CI: 1.31-6.80, p-value $=0.01)($ Table 1$)$.

\section{Discussion}

In this study, socio-economic characteristics, personal behaviors, patient related factors, care provider and system related factors, and knowledge were not statistically associated with TB treatment interruption. The absence of statistical associations between these factors and TB treatment interruption in this study does not mean that they are not important factors contributing to the occurrence of TB treatment interruption. These might be due to possible variations in the socio-economic, behavioral, and health status of the community. But, alcohol consumption, HIV co-infection, traditional/herbal medicine use, smoking habits, and waiting time at the health facility of $\geq 30$ minutes were found to be statistically associated with the occurrence of TB treatment interruption.

In this study, TB/HIV co-infection was a significant factor in TB treatment interruption, which is consistent with studies conducted in Nigeria, London, and Kenya. ${ }^{14,20,21}$ This could be due to drug side effects and the failure of health workers to counsel patients on the potential side effects. Tuberculosis patients who consume alcohol are at increased risk of TB treatment interruption, as also demonstrated in studies conducted in Nandi County (Kenya), South Africa and Nairobi province (Kenya). ${ }^{3,20,22}$ Alcohol might cause patients to forget to take their pills or to attend their scheduled appointment. Cigarette smoking has also been shown to be significantly associated with TB treatment interruption, as demonstrated in the studies conducted in Plateau and Lagos states (Nigeria). ${ }^{13,14}$ How smoking influences patients to interrupt their TB treatment is not yet understood.

Tuberculosis patients who reported an average waiting time of more than or equal to 30 minutes at a health facility were significantly more at risk for TB treatment interruption, a finding similar to that of a study conducted in Kenya. ${ }^{3,10}$ This might be due to patients feeling discouraged by long waiting times and subsequently less inclined to return to health facilities for TB drugs. In addition, the long waiting times experienced by TB drugtaking clients who have traveled a large distance might expose them to further expense, which then leads them to 
Table I Multivariate Analysis Showing Determinants for TB Treatment Interruption in South Ari District, Southern Ethiopia, 202

\begin{tabular}{|c|c|c|c|c|c|}
\hline \multicolumn{2}{|l|}{ Variables } & \multirow{2}{*}{$\begin{array}{l}\text { Cases } \\
n\end{array}$} & \multirow{2}{*}{$\begin{array}{l}\text { Controls } \\
n\end{array}$} & \multirow[t]{2}{*}{ COR with $95 \% \mathrm{Cl}$} & \multirow[t]{2}{*}{ AOR with $95 \% \mathrm{CI}$} \\
\hline & & & & & \\
\hline \multirow[t]{2}{*}{ Sex } & Male & 57 & 98 & 1.0 & \\
\hline & Female & 25 & 69 & $0.62(0.36-1.10)$ & $0.9(0.36-1.10)$ \\
\hline \multirow[t]{5}{*}{ Age } & $15-24$ & 9 & 46 & $0.34(0.15-0.79)$ & $2.1(0.60-1.21)$ \\
\hline & $25-34$ & 33 & 58 & 1.0 & 1.0 \\
\hline & $35-44$ & 12 & 30 & $0.70(0.32-1.56)$ & $3.2(3.6-4.10)$ \\
\hline & $45-54$ & 15 & 25 & $1.05(0.49-2.28)$ & $9.5(5.9-7.10)$ \\
\hline & $\geq 55$ & 13 & 8 & $2.86(1.07-7.60)$ & $5.9(3.9-4.10)$ \\
\hline \multirow[t]{5}{*}{ Marital status } & Married & 33 & 69 & 1.0 & 1.0 \\
\hline & Unmarried & 11 & 43 & $0.53(0.24-1.17)$ & $4.5(2.3-4.10)$ \\
\hline & Separated & 5 & 25 & $0.42(0.15-1.19)$ & $5.5(3.9-5.13)$ \\
\hline & Divorced & 17 & 12 & $2.96(1.27-6.91)$ & $3.4(1.2-2.19)$ \\
\hline & Widowed & 16 & 18 & $1.86(0.84-4.10)$ & $5.52(3.3-5.10)$ \\
\hline \multirow[t]{2}{*}{ Level of knowledge } & Good & 26 & 90 & 1.0 & 1.0 \\
\hline & Poor & 56 & 77 & $2.52(1.44-4.44)$ & $5.2(1.32-4.74)$ \\
\hline \multirow[t]{2}{*}{ Alcohol consumption } & Yes & 51 & 40 & $5.22(2.95-9.24)$ & $2.99(I .4 I-6.36)^{*}$ \\
\hline & No & 31 & 127 & 1.0 & 1.0 \\
\hline \multirow[t]{2}{*}{ Khat chewing } & Yes & 32 & 46 & $1.68(0.96-2.94)$ & $1.25(0.35-0.94)$ \\
\hline & No & 50 & $12 \mid$ & 1.0 & 1.0 \\
\hline \multirow[t]{2}{*}{ Smoking habits } & Yes & 36 & 28 & $3.89(2.14-7.05)$ & $2.82(1.14-6.94)^{*}$ \\
\hline & No & 46 & 139 & 1.0 & 1.0 \\
\hline \multirow[t]{2}{*}{ Sputum result at diagnosis } & $+\mathrm{ve}$ & 75 & 142 & $3.08(1.33-6.67)$ & $2.04(1.33-3.97)$ \\
\hline & -ve & 7 & 25 & 1.0 & 1.0 \\
\hline \multirow[t]{2}{*}{ TB category } & New & 50 & 134 & 1.0 & 1.0 \\
\hline & Previously treated & 32 & 33 & $2.60(1.45-4.66)$ & $1.94(2.94-3.95)$ \\
\hline \multirow[t]{2}{*}{ HIV status } & -ve & 31 & 27 & $3.15(1.72-5.78)$ & $1.58(1.85-4.29)^{*}$ \\
\hline & tve & 51 & 140 & 1.0 & 1.0 \\
\hline \multirow[t]{2}{*}{ Traditional/herbal medicine use } & Yes & 34 & 22 & $1.86(1.07-3.25)$ & $2.35(1.05-5.24)^{*}$ \\
\hline & No & 48 & 145 & 1.0 & 1.0 \\
\hline \multirow[t]{2}{*}{ Waiting time at HF } & $<30$ minutes & 48 & 139 & 1.0 & 1.0 \\
\hline & $\geq 30$ minutes & 34 & 28 & $3.52(1.93-6.40)$ & $2.98(1.31-6.80)^{*}$ \\
\hline \multirow[t]{2}{*}{ Counseling before initiation } & Yes & 56 & 129 & 1.0 & 1.0 \\
\hline & No & 26 & 38 & $1.58(0.87-2.84)$ & $2.35(0.98-2.75)$ \\
\hline
\end{tabular}


Table I (Continued).

\begin{tabular}{|c|c|c|c|c|c|}
\hline \multicolumn{2}{|l|}{ Variables } & \multirow{2}{*}{$\begin{array}{l}\text { Cases } \\
n\end{array}$} & \multirow{2}{*}{$\begin{array}{l}\text { Controls } \\
\mathbf{n}\end{array}$} & \multirow[t]{2}{*}{ COR with $95 \% \mathrm{Cl}$} & \multirow[t]{2}{*}{ AOR with $95 \% \mathrm{Cl}$} \\
\hline & & & & & \\
\hline \multirow[t]{2}{*}{ TB treatment supporter } & Yes & 21 & 112 & 1.0 & 1.0 \\
\hline & No & 61 & 55 & $5.92(3.27-10.69)$ & $3.08(1.33-2.39)$ \\
\hline \multirow[t]{2}{*}{ Stigmatization } & Yes & 29 & 28 & $2.72(1.48-4.99)$ & $2.05(0.45-2.03)$ \\
\hline & No & 53 & 139 & 1.0 & 1.0 \\
\hline
\end{tabular}

Note: ${ }^{*} \mathrm{p}$-value $\leq 0.05$; ref $=$ reference, $\mathrm{Cl}=$ confidence interval, $\mathrm{OR}=$ odds ratio.

interrupt their TB drug intake follow-up before being cured. Furthermore, long waiting times mean longer absences from the workplace, which can lead to conflict with managers, resulting in further interruption to TB drug treatment follow-up.

Traditional/herbal medicine use was a significant determinant for TB treatment interruption, as also shown in a South African study. ${ }^{22}$ This might be because it appears to produce results more quickly than modern medicine and patients may thus interrupt their TB treatment to use traditional/herbal medicines for a short-term fix. In addition, it might be possible to access traditional medicine locally, thus avoiding the time and expense of traveling to a health facility, which might lead patients to interrupt their TB drug-taking.

In this study, high alcohol consumption is a determinant factor for TB drug-taking interruption, in line with a study conducted in Nigeria. ${ }^{23}$ This might be because high alcohol consumption can cause liver damage and sleep disturbance (a double burden), impaired judgment and amnesia (which causes patients to forget their appointments and to take their pills), all of which can ultimately lead them to interrupt their regular follow-up of TB drug treatment.

\section{Limitations of the Study}

In this study, we tried to identify determinants of treatment interruption among drug susceptible pulmonary tuberculosis patients using analytical methods able to assess risk factors including waiting time, distance from the health facility, cost of medications, forgetfulness, the use of herbal medication, and co-infection with HIV. However, the limitation of this study was that it failed to include comorbid diseases, physical exercise, and dietary patterns.

\section{Conclusions}

The study revealed that alcohol consumption, a waiting time at the health facility of $\geq 30$ minutes, smoking habits, traditional medicine use and co-infection with HIV were potential determinants for the occurrence of treatment interruption. Enhancing public health education, designing strategies that emphasize patients with HIV co-infection and suggesting to TB clinic health personnel that waiting times be reduced are recommended.

The government of Ethiopia and the national TB control program should support and promote the involvement of all eligible private health care providers to ensure availability and accessibility of the services to patients. The National TB Training Center in Ethiopia should include training of TB control service providers on interpersonal communication to improve relationships between patients and health care providers. Generally, enhancing public health education on the dangers of alcohol use and cigarette smoking, designing strategies that emphasize patients with HIV co-infection and suggesting to TB clinic health personnel that waiting times be reduced should occur to address TB treatment interruption. Further studies are needed focusing on comorbid diseases, physical exercise and dietary patterns.

\section{Data Sharing Statement}

Data can be accessed upon request of the corresponding author.

\section{Ethics Approval and Consent to Participate}

Before the study began ethical clearance was obtained from the ethical review committee of Debre Markos University, College of Health Science. A permission letter was received from the zonal health department of South Omo zone and South Ari district health office. Written consent was obtained from all study participants after describing to them all the issues related to the study in detail. Their details were stored carefully and all efforts were made to maintain confidentiality related to the 
information provided and recorded in the data sheet. For participants between 15 and 17 years of age, consent was obtained from their guardians. To maintain confidentiality, the information of the study participants was not disclosed to anyone other than the principal investigators. Generally, this study was conducted in accordance with the World Medical Association Declaration of Helsinki.

\section{Acknowledgments}

The authors extended their special thanks to both data collectors and supervisors.

\section{Author Contributions}

All authors made a significant contribution to the work reported (conception, study design, execution, acquisition of data, analysis and interpretation, or in all these areas; took part in drafting, revising or critically reviewing the article); gave final approval of the version to be published; have agreed on the journal to which the article has been submitted; and agree to be accountable for all aspects of the work.

\section{Funding}

There is no funding to report.

\section{Disclosure}

The authors reported no conflicts of interest for this work.

\section{References}

1. World Health Organization: Tuberculosis surveillance and monitoring in Europe 2019: 2017 data. 2019.

2. Sachdeva KS, Kumar A, Dewan P, Kumar A, Satyanarayana S. New vision for Revised National Tuberculosis Control Programme (RNTCP): universal access-"reaching the un-reached". Indian J Med Res. 2012;135(5):690.

3. Wanyonyi AW, Wanjala PM, Githuku J, Oyugi E, Kutima H. Factors associated with interruption of tuberculosis treatment among patients in Nandi County, Kenya 2015. Pan Afr Med J. 2017;28(Suppl 1). doi:10.11604/pamj.supp.2017.28.1.9347

4. Mzembe T. Prevalence of Mycobacterium tuberculosis infection among adolescents in rural KwaZulu-Natal, South Africa. LSHTM. 2020.

5. Genet C, Andualem T, Melese A, Mulu W, Mekonnen F, Abera B. Quality of care for tuberculosis patients in public health facilities of Debre Tabor town, Northwest Ethiopia. PLoS One. 2020;15(6): e0234988. doi:10.1371/journal.pone.0234988

6. Weil D, Marinkovic K, Kasaeva T. Back to the future, again: greater leadership, collaboration and accountability to accelerate progress to end TB. BMC Med. 2018;16(1):1-4. doi:10.1186/s12916-018-1165-9

7. FMOH. National comprehensive $\mathrm{TB}$ and $\mathrm{TB} / \mathrm{HIV}$ training manual health care workrs. 2016: 47-48. Available from: https://www.slide share.net/suleymanfantahun/new-ethiopian-tb-guildline-november -2016. Accessed April 28, 2021.
8. Hirpa S, Medhin G, Girma B, et al. Determinants of multidrug-resistant tuberculosis in patients who underwent first-line treatment in Addis Ababa: a case control study. BMC Public Health. 2013;13(1):782. doi:10.1186/1471-2458-13-782

9. Gobena D, Ameya G, Haile K, Abreha G, Worku Y, Debela T. Predictor of multidrug resistant tuberculosis in southwestern part of Ethiopia: a case control study. Ann Clin Microbiol Antimicrob. 2018;17(1):30. doi:10.1186/s12941-018-0283-8

10. Wanyonyi AW: Factors associated with interruption of tuberculosis treatment among patients in Nandi county, Kenya (unpublished). COHES-JKUAT; 2018.

11. Adane AA, Alene KA, Koye DN, Zeleke BM. Non-adherence to anti-tuberculosis treatment and determinant factors among patients with tuberculosis in northwest Ethiopia. PLoS One. 2013;8(11): e78791. doi:10.1371/journal.pone.0078791

12. Jakubowiak W, Bogorodskaya E, Borisov S, Danilova I. Treatment interruptions and duration associated with default among new patients with tuberculosis in six regions of Russia. Int $J$ Infect Dis. 2008;13(3):362-368. doi:10.1016/j.ijid.2008.07.015

13. $\mathrm{Lm} \mathrm{I}$, Is H. Factors associated with interruption of treatment among pulmonary tuberculosis. Pan Afr Med J. 2014;17(78).

14. Adejumo OA, Daniel OJ, Otesanya AF, Ashipa T, Adejumo EN, Abdur-Razzaq HA. Factors affecting treatment interruption among tb patients in lagos nigeria: isthere any need for treatment supporters? Int J Clin Med. 2016;07(06):389-398. doi:10.4236/ijcm.2016.76042

15. World Health Organisation. Global tuberculosis report.Geneva: World Health Organiztion; 2018. Available from: www.who.int/tb/ data. Accessed April 28, 2021.

16. Desissa F, Workineh T, Beyene T. Risk factors for the occurrence of multidrug-resistant tuberculosis among patients undergoing multidrug-resistant tuberculosis treatment in East Shoa, Ethiopia. BMC Public Health. 2018;18(1):422. doi:10.1186/s12889-018-5371-3

17. Workicho A, Kassahun W, Alemseged F. Risk factors for multidrug-resistant tuberculosis among tuberculosis patients: a case-control study. Infect Drug Resist. 2017;10:91. doi:10.2147/ IDR.S126274

18. Tesfay K, Tesfay S, Nigus E, Gebreyesus A, Gebreegziabiher D, Adane K. More than half of presumptive multidrug-resistant cases referred to a tuberculosis referral laboratory in the Tigray region of Ethiopia are multidrug resistant. Int $J$ Mycobacteriol. 2016;5 (3):324-327. doi:10.1016/j.ijmyco.2016.07.007

19. Mulu W, Mekkonnen D, Yimer M, Admassu A, Abera B. Risk factors for multidrug resistant tuberculosis patients in Amhara National Regional State. Afr Health Sci. 2015;15(2):368-377. doi:10.4314/ahs.v15i2.9

20. Muture BN, Keraka MN, Kimuu PK, Kabiru EW, Ombeka VO, Oguya F. Factors associated with default from treatment among tuberculosis patients in Nairobi province, Kenya: a case control study. BMC Public Health. 2011;11(1):696. doi:10.1186/1471-2458-11-696

21. Breen RA, Miller RF, Gorsuch T, et al. Adverse events and treatment interruption in tuberculosis patients with and without HIV co-infection. Thorax. 2006;61(9):791-794. doi:10.1136/ thx.2006.058867

22. Finlay A, Lancaster J, Holtz TH, Weyer K, Miranda A, van der Walt M. Patient-and provider-level risk factors associated with default from tuberculosis treatment, South Africa, 2002: a case-control study. BMC Public Health. 2012;12(1):56. doi:10.1186/ 1471-2458-12-56

23. Ibrahim LM, Hadejia IS, Nguku P, et al. Factors associated with interruption of treatment among pulmonary tuberculosis patients in Plateau State, Nigeria. 2011. Pan Afr Med J. 2014;17:78. doi:10.11604/pamj.2014.17.78.3464 


\section{Publish your work in this journal}

Patient Preference and Adherence is an international, peer-reviewed, open access journal that focusing on the growing importance of patient preference and adherence throughout the therapeutic continuum. Patient satisfaction, acceptability, quality of life, compliance, persistence and their role in developing new therapeutic modalities and compounds to optimize clinical outcomes for existing disease

states are major areas of interest for the journal. This journal has been accepted for indexing on PubMed Central. The manuscript management system is completely online and includes a very quick and fair peer-review system, which is all easy to use. Visit http:// www.dovepress.com/testimonials.php to read real quotes from published authors.

Submit your manuscript here: https://www.dovepress.com/patient-preference-and-adherence-journal 